In a note accompanying the ordinary diet table it is officially stated that this "table gives the four classes of solid constituents in substantially the following proportions:

Nitrogenous or plastic material, about one hundred and forty grams; fat, about sixty-two grams; carbohydrates, (starch, sugar, etc.,) about four hundred and fifty grams, and salines, about twenty-six grams; and with about two thousand and two hundred and fifty grams of water. Although these quantities are somewhat in excess of the estimates for "healthy adults at rest," they are none too great for convalescents in whom tissue metamorphosis is being carried on, not only in the interest of repair of present waste from use, but in the interest of repair of past waste from disease, a point which should not be overlooked in the construction of hospital dietaries. In making any changes from the above, the substituted article should be in such quantities and of such kinds as to furnish constituents equivalent to those of the articles replaced."

Recognition is made of the fact that climate and season may render modifications necessary.

In my own experience, substitutions are not so frequent as changes in the relative proportions of some of the articles, notably milk and eggs, which are consumed in greater quantity than given in the supply table, while a reduction is not infrequently made in the meat allowance.

But without regard to any change in the articles or quantities of subsistence, it is proper to state that the quality of the various articles of food supplies as given by the analyses quoted in the foregoing description of each, is probably better than that upon which the official analysis of the diet table was originally based. At any rate, careful calculation of the composition of the articles named shows even larger proportions of nutritive constituents than given in the official note.

\section{REPORT OF FOUR HUNDRED CASES OF INTUBATION OF THE LARYNX, WITH PRACTICAL DEDUCTIONS.}

Read in the Section of Diseases of Children, at the Forty-third Annual Meeting of the American Medical Association, held at Detroit, Mich.. June, 1892.

BY F. E. WAXHAM, M.D.,

PROFESSOR OP LARYNGOLOGY, RHINOLOGY AND DISEASES OF CHILDREN, COLLEGE OF PHYSICIANS AND SURGEONS OF CHICAGO.

Intupation of the larynx has been so frequently and unfavorably compared with tracheotomy that I feel it my duty to report the cases coming under my observation, and to point out some of the reasons for unfavorable results.

It has been my experience, largely through the courtesy of my confreres, to have now operated on something over four hundred cases, with results that might well make any one an enthusiastic supporter of the operation.

It should be remarked that these operations were performed in private practice in a large city and its suburbs, without selection, upon all cases dying from laryngeal obstruction, without reference to age, malignancy of disease or unfavorable surroundings. It must be remarked also that a great many of these cases were experimental cases, and many could have been saved with the more modem instruments and with the judgment and skill coming with larger experience.
RECORD OF CASES,

Age (under) 1 year.

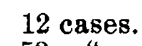

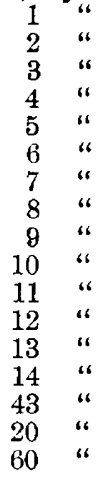

$\begin{aligned} 12 & \text { cases. } \\ 52 & \text { “ } \\ 70 & \text { " } \\ 69 & \text { “ } \\ 79 & \text { " } \\ 39 & \text { “ } \\ 25 & \text { “ } \\ 25 & \text { " } \\ 10 & \text { " } \\ 6 & \text { " } \\ 5 & \text { " } \\ 1 & \text { " } \\ 1 & \text { " } \\ 1 & \text { ": } \\ 1 & \text { " } \\ 1 & \text { " } \\ 1 & \end{aligned}$

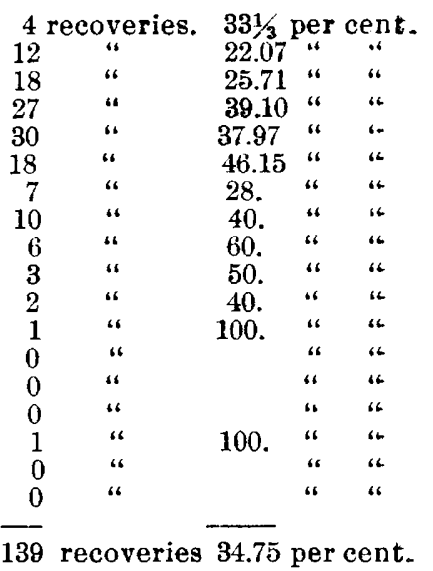

It should be observed that of these cases 134 were under the age of 3 years, with recoveries amounting to 25.37 per cent, an age at which tracheotomy is rarely successful. It will be observed that in the first hundred cases there were twenty-seven recoveries, in the second hundred thirty-four, in the third hundred forty, and in the fourth hundred thirtyeight. Improved instruments, improved methods of feeding, greater watchfulness and judgment in the management of cases, and the almost universal administration of the bichloride of mercury after the first hundred cases, undoubtedly accounts for the larger ratio of recoveries.

Why is it that we so frequently hear of unfavorable experiences?

1. On account of the difficulty of the operation.

2 . Because judgment is not exercised in the selection of the proper tube.

3. Patients are frequently allowed to die from obstruction below the tube which in many cases can be overcome.

4. On account of the absence of careful nursingand the most watchful attention.

Undoubtedly this operation requires more delicacy of "technique" than almost any other operation in surgery. The operation is a far more difficult one than tracheotomy, and few there are who can properly do it without long and special training. It is an operation for the specialist, the expert and those especially dextrous, if best results are to be obtained. Too frequently operators without special aptitude and with no training whatever attempt the operation, the result is disastrous and after a few trials the operation is denounced. In every city this work should be done by one or two operators, who should spare no effort in becoming skilful, and by doing all these operations would soon acquire sufficient experience to insure splendid results. In country districts or in small towns where the operation is not of ten required, tracheotomy will be found to be far more satisfactory, as no one can become skilful or maintain confidence in doing the operation on two or three cases a year. The result will depend in no small measure upon the judgment displayed in the selection of the proper tube. To introduce a large and tightly fitting tube that cannot be expelled in case of obstruction below it, and to leave the patient in fancied security, is to cordially invite disaster. A loosely fitting tube should be employed, and no harm is done if it is expelled every day, providing the operator replaces it, as he should, gently, skilfully and with no injury. If a 
tube is rejected several times a day a somewhat larger one should be used. The attendants should always be instructed that in case of emergency from sudden occlusion of the tube the patient should be inverted, and if by shaking the child in this position the tube is not expelled, the finger should be forcibly placed upon the trachea below the tube, when it can be crowded out.

Many a case can be saved by the removal of a tube on the first indication of membrane below it. The indications of partially detached membrane below the tube are very apparent and should not be heedlessly overlooked. The occurrence of a hoarse squeaking cough, with sometimes a decided flapping sound in the trachea, should call for the immediate removal of the tube. When this is done, the expulsive cough that follows will in a great majority of cases expel the membranous cast causing the obstruction. In this manner I have often secured complete casts of the trachea and even larger bronchial tubes, of which these specimens are but a few examples. By a little persistence it will rarely happen that these casts cannot be secured just as effectively as by a tracheotomy.

The success of the operation does not depend simply upon the ability of introducing a tube into the larynx. The careful nursing and feeding and the faithful continuation of treatment, as well as prompt interference in case of emergency, are most important factors in the successful management of a case.

But little difficulty is usually experienced in feeding the patient in the inclined position. In the absence of a trained nurse the physician himself should personally superintend the matter of feeding, otherwise insufficient nourishment will be given. I have often been able to give a half a pint of milk to a patient without difficulty when parents have declared that it was impossible to "get anything down." It is extremely important to continue with the same line of treatment after the operation that was instituted before. Of these measures I believe the most important to be the use of the steam atomizer, the internal administration of iron and bichloride of mercury in frequent full doses, and local disinfection. The most efficient local antiseptics and those giving me the greatest satisfaction have been the bichloride of mercury and peroxide of hydrogen.

To recapitulate: In order to obtain the most satisfactory results, the operation should be performed only by those who by special aptitude and careful training are capable of doing it quickly, gently and skilfully.

The greatest judgment should be exercised in the selection of the tube. Emergencies should be promptly met, the case carefully watched, and every detail of management carefully considered.

240 Wabash Ave.

\section{ACUTE BRONCHITIS IN CHILDREN.}

Read in the Section of Disenses of Children, at the Forty-third annual meeting of the American Medical Association, held at

BY C. L. DODGE, M.D., OF KINGSTON, N. Y.

Certain anatomical peculiarities of the child's lung deserve attention before entering upon a description of the acute affections to which it is most frequently subject. These peculiarities are of embryonic type, and are present to a greater or less extent up to the fifth year. In the fotus the bronchial tubes are relatively large, while the alveoli are mere bud-like dilatations, "as if Nature had laid out a bronchial tree of generous proportions at the outset, to meet the demands of new-born existence and allow for its subsequent growth." The connective tissue in the fotal lung is everywhere a delicate meshwork, but loosely retaining the bloodvessels, tending to abundant cell-proliferation, and occupying a far greater relative space than in the adult, - the air vesicles and intervening connective tissue being about equal in extent. The lining membrane of the bronchial tubes, with its rich net work of capillaries, is but loosely bound to the muscular walls, and lies in folds. The alveolar walls are thick, and their structure comparatively loose and yielding; their inner surfaces readily shed and proliferate epithelium, as does the bronchial musous membrane; moreover, the cells.in both instances are relatively larger than those of an adult lung. The blood-vessels, being loosely restrained, readily dilate and encroach upon space properly belonging to the alveoli, and readily cause partial collapse. The thoracic walls are soft and yielding, while the muscles of the throat, bronchi, and chest are relatively less developed and far weaker than in the adult. These peculiarities (which, of course, gradually become less marked after birth as age advances) should be borne in mind, as showing the ease with which serious encroachment upon respiratory space may take place in certain inflammatory conditions.

By the fifth year, in a healthy child, the loose connective tissue has become condensed, properly restraining the capillaries and binding the bronchial lining much more firmly to the walls. New alveoli have been produced, and the proper relative capacity of the air-spaces to the bronchial tubes has been established. The lung has now become anatomically adult, although it still preserves in a measure its: faculty of easily shedding epithelium.

Inflammation of the bronchial tubes or bronchitis is one of the most common diseases of early life, and no disease in the nosological list presents greater variations as to type and severity than bronchitis as it occurs in infancy and childhood. It is a matter of common observation for children to pass through the stages of acute bronchitis of mild grade with no. medical treatment whatever, and on the other hand we know when abnormally severe it is justly one of the most dreaded diseases of childhood. Bronchitis proper, that is inflammation of the larger tubes, is a more frequent disease than is generally supposed. While I believe with Dr. Morrill that "bronchitis" is credited as a cause of death among children in many cases where the correctness of the diagnosis is open to doubt, I also believe that many cases of bronchitis. are diagnosticated, or at least termed inflammation: of the lungs. It is well known that bronchitis, among the laity is considered to be a species of throat disease, sub-acute or chronic in character: now to tell many parents holding these views that their child is suffering from bronchitis, when all the symptoms point to a severe acute disease, is to raise suspicion in their minds at once as to the correctness of the diagnosis. Consequently many physicians call every severe case of hronchitis, inflammation of the

I Dr. F. Gordon Morrill, in Keating's Cyclopedia, to whom I exprese I Dr. F. Gordon Morril, in Keating's Cyclopedia, to whom
my thanks for the free use which I have made of his paper. 